Check for updates

Department of Primary Care and Public Health, Imperial College London, London W6 8RF

2 Communications and Public Affairs, Imperial College London, London, UK

Correspondence to: S Saxena s.saxena@imperial.ac.uk @soniaksaxe na on Twitter

Cite this as: $B M J 2021 ; 374: \mathrm{n} 1866$ http://dx.doi.org/10.1136/bmj.n1866 Published: 23 July 2021

\section{Should the UK vaccinate children and adolescents against covid-19?}

\author{
The UK is an outlier in holding off vaccinating healthy 12-17 year olds \\ Sonia Saxena, ${ }^{1}$ Helen Skirrow, ${ }^{1}$ Kate Wighton ${ }^{2}$
}

The UK Joint Committee on Vaccination and Immunisation (JCVI) has now recommended covid-19 vaccination for select groups of adolescents. Those newly eligible comprise 12-15 year olds with underlying conditions that may place them at increased risk of serious covid-19 infection, 17 year olds who are within three months of turning 18, and adolescents living with someone who is immunosuppressed. ${ }^{1}$ Young people aged 16 to 17 who are at higher risk of serious covid-19 were already eligible.

The decision came after the Medicines and Healthcare Products Regulatory Agency approved

Pfizer-BioNTech's covid-19 vaccine for use in children aged over 12 years. ${ }^{2}$ The JCVI decision triggered public debate because unlike several other high income countries, including the United States ${ }^{3}$ and Canada, 4 the UK will not offer covid-19 vaccines to all children aged over 12 years.

The UK has vaccinated most of its high risk population against covid-19. Over two thirds of adults aged over 18 years have received two doses. ${ }^{5}$

However, breaking the chain of transmission needs close to $85 \%$ of the whole population to be immune. ${ }^{6}$ Children and adolescents, whose lives have been disrupted by school closures, isolation, and social restrictions, ${ }^{7}$ make up $21 \%$ of the population. As restrictions lift, cases are rising fast in this younger unvaccinated population. ${ }^{5}$

\section{Benefits and risks}

Extending covid-19 vaccination to protect adolescents aged 12 to 15 years with medical conditions such as Down's syndrome seems justified, given their increased risk of severe infection. ${ }^{8}$ However, the vaccine offers less benefit for healthy adolescents, who tend to have a relatively mild illness. Their risk of death or hospital admission from covid-19 is very low; one study estimated the risk of catching and dying of covid-19 for all children in England as two in a million. 9 Complications of covid-19 infection, including paediatric multisystem inflammatory syndrome, are also rare. ${ }^{10}$

Although most healthy adolescents recover after covid-19, some have reported persistent symptoms such as fatigue and headaches lasting 3-6 months. ${ }^{11} 12$ Prevalence estimates for long covid vary, partly because symptoms are hard to separate from the wider effects of isolation and lockdowns on adolescents, but vaccination could reduce the health burden from long covid. Covid-19 vaccines reduce the risk of new variants emerging, and even a single dose can halve transmission rates. ${ }^{13}$ Thus vaccinating healthy adolescents could afford them better health while reducing disruption to their education and protecting social contacts.

Parents' concerns centre around vaccine safety. ${ }^{14}$ Only half of parents of secondary school children say they would definitely want them to receive a covid-19 vaccination. ${ }^{5}$ The Pfizer-BioNTech vaccine trial in adolescents reported $100 \%$ efficacy at preventing covid-19 infection, without serious side effects. ${ }^{15}$ Regulatory agencies globally say vaccine benefits outweigh infection risks, and millions of over $12 \mathrm{~S}$ have been vaccinated safely. ${ }^{316} \mathrm{~A}$ few vaccinated adolescents in the US and Israel have experienced heart inflammation (pericarditis and myocarditis). ${ }^{1718}$ The US Centers for Disease Control and Prevention confirmed 633 cases among the millions vaccinated to date. ${ }^{19}$ Most of the cases were mild and the young people recovered quickly. ${ }^{20}$

Even rare side effects among adolescents could undermine public trust in other lifesaving programmes such as human papillomavirus vaccination, which has reduced deaths from cervical cancer. Parents and teenagers should be reassured that any new vaccination programme is closely monitored and reports of side effects are quickly investigated. Parents should also be informed there are no plans to vaccinate children under 12 in the UK as there is currently insufficient evidence that vaccinating this age group is safe, effective, or acceptable to parents. However, trials are under way.

\section{Unheard voices}

Young people have sacrificed their freedom in order to protect elderly relatives and family members. Yet from the start of the pandemic, 9 in 10 young people felt excluded from the covid-19 conversation by scientists and policy makers. ${ }^{21}$ Most young people aged 16-29 express willingness to be vaccinated against covid-19 if offered, ${ }^{5}$ though in the UK those aged 16 and 17 seem more cautious than people aged $18-24 .^{22}$

Involving patients and the public in decisions about their health is an embedded core principle for health professionals. However, patient and public involvement has been largely missing from the pandemic response so far. Consulting young people and parents to understand their perspectives about getting the vaccine must now be a priority for a sustainable vaccination programme. This would also send a positive signal to the next generation that they virus. By getting vaccinated, adolescents could protect themselves against the risk of long covid and help the UK's control efforts. But they may prefer to wait their turn behind adults in other countries that have greater need. are an integral part of society's efforts to control the 
Last week's announcement for selective vaccination of adolescents seems justifiable given the benefits to adolescents and households at high risk of severe covid-19 infection, although it leaves the UK an outlier among rich countries. For now, decisions about mass vaccination of healthy adolescents will be guided by the pandemic's impacts, and new data about the safety and effectiveness of vaccinating this age group. The effectiveness of any vaccine programme depends on uptake, so young people's voices should be part of ongoing reviews of covid-19 policy. Today's adolescents will make decisions about our health in years to come. We need to listen to them.

Competing interests: The BM/ has judged that there are no disqualifying financial ties to commercial companies. The authors declare the following other interests. SS is supported by the NIHR Northwest London Applied Research Collaboration, NIHR School for Public Health Research and holds funding from the Daily Mile Foundation. HS is funded by an NIHR doctoral research fellowship number 300907. Further details of The BM/policy on financial interests is here: https://www.bmj.com/sites/default/files/attachments/resources/2016/03/16-current-bmj-education-coi-form.pdf.

Provenance and peer review: Commissioned; not externally peer reviewed

We thank the parents and young people who contributed to this editorial, commented on the content, and suggested revisions that helped frame our key messages, including Rosenna Sandbrook, Nina Pollok, Kim Foley, Rakhee Shah, Arti Maini, Amanda Young, and Maya Young.

1 Public Health England. Joint Committee on Vaccination and Immunisation issues advice on COVID-19 vaccination of children and young people. Press release, 19 July 2021.

https://www.gov.uk/government/news/jcvi-issues-advice-on-covid-19-vaccination-of-childrenand-young-people.

2 MHRA. The MHRA concludes positive safety profile for Pfizer/BioNTech vaccine in 12- to 15-year-olds. 4 Jun 2021. https://www.gov.uk/government/news/the-mhra-concludes-positivesafety-profile-for-pfizerbiontech-vaccine-in-12-to-15-year-olds.

3 CDC, National Center for Immunization and Respiratory Diseases, Division of Viral Diseases. COVID-19 vaccines for children and teens. Updated 27 May 2021. https://www.cdc.gov/coronavirus/2019-ncov/vaccines/recommendations/adolescents.html.

4 National Advisory Committee on Immunization. Recommendations on the use of covid-19 vaccines. 2021. https://www.canada.ca/en/public-health/services/immunization/national-advisory-committee-on-immunization-naci/recommendations-use-covid-19-vaccines.html.

5 Office for National Statistics. Coronavirus (COVID-19) latest insights: vaccines. 16 Jul 2021. https://www.ons.gov.uk/peoplepopulationandcommunity/healthandsocialcare/conditionsanddiseases/articles/coronaviruscovid19/latestinsights

6 Yates K. (How) can we reach herd immunity? BMJ Opinion, 16 Jul 2021. https://blogs.bmj.com/bmj/2021/07/16/kit-yates-how-can-we-reach-herd-immunity/

7 Viner R, Russell S, Saulle R, etal. Impacts of school closures on physical and mental health of children and young people: a systematic review. [Preprint.] medRxiv2021:2021.02.10.21251526. doi: 10.1101/2021.02.10.21251526

8 Ward JL, Harwood R, Smith C, etal. Risk factors for intensive care admission and death amongst children and young people admitted to hospital with COVID-19 and PIMS-TS in England during the first pandemic year. [Preprint.]medRxiv 2021:2021.07.01.21259785. doi: 10.1101/2021.07.01.21259785

9 Smith C, Odd D, Harwood R, etal. Deaths in children and young people in England following SARS-CoV-2 infection during the first pandemic year: a national study using linked mandatory child death reporting data. [Preprint.] 2021:2021.07.07.21259779. doi: 10.1101/2021.07.07.21259779

10 Whittaker E, Bamford A, Kenny J, etalPIMS-TS Study Group and EUCLIDS and PERFORM Consortia. Clinical characteristics of 58 children with a pediatric inflammatory multisystem syndrome temporally associated with SARS-CoV-2. JAMA 2020;324:259-69. doi: 10.1001/jama.2020.10369 pmid: 32511692

11 ONS. Prevalence of ongoing symptoms following coronavirus (covid-19) infection in the UK. 1 July 2021. https://www.ons.gov.uk/peoplepopulationandcommunity/healthandsocialcare/conditionsanddiseases/bulletins/prevalenceofongoingsymptomsfollowingcoronaviruscovid19infectionintheuk/1july2021.

12 Osmanov IM, Spiridonova E, Bobkova P, etalSechenov StopCOVID Research Team. Risk factors for long covid in previously hospitalised children using the ISARIC Global follow-up protocol: A prospective cohort study. Eur Respir /2021;2101341. doi: 10.1183/13993003.01341-2021. pmid: 34210789

13 Harris RJ, Hall JA, Zaidi A, Andrews NJ, Dunbar JK, Dabrera G. Effect of vaccination on household transmission of SARS-CoV-2 in England. N Engl J Med 2021. doi: 10.1056/NEJMc2107717 pmid: 34161702

14 Bell S, Clarke R, Mounier-Jack S, Walker JL, Paterson P. Parents' and guardians' views on the acceptability of a future COVID-19 vaccine: A multi-methods study in England. Vaccine 2020;38:7789-98. doi: 10.1016/j.vaccine.2020.10.027 pmid: 33109389

15 Frenck RW, JrKlein NP, Kitchin N, etalC4591001 Clinical Trial Group. Safety, immunogenicity, and efficacy of the BNT162b2 covid-19 vaccine in adolescents. N Engl J Med 2021;385:239-50. doi: 10.1056/NEJMoa2107456 pmid: 34043894
16 European Medicines Agency. First covid-19 vaccine approved for children aged 12 to 15 in EU. 2021. https://www.ema.europa.eu/en/news/first-covid-19-vaccine-approved-children-aged-1215-eu.

17 Centers for Disease Control and Prevention. Myocarditis and pericarditis following mRNA covid-19 vaccination. 2021. https://www.cdc.gov/coronavirus/2019-ncov/vaccines/safety/myocarditis.html.

18 Vogel GC-FJ. Israel reports link between rare cases of heart inflammation and COVID-19 vaccination in young men. Science 2021 Jun. https://www.sciencemag.org/news/2021/06/israel-reports-linkbetween-rare-cases-heart-inflammation-and-covid-19-vaccination.

19 Centers for Disease Control and Prevention. Selected adverse events reported after covid-19 vaccination. Updated 13 Jul 2021. https://www.cdc.gov/coronavirus/2019-ncov/vaccines/safety/adverse-events.html

20 Wise J. Covid-19: Should we be worried about reports of myocarditis and pericarditis after mRNA vaccines?BM/2021;373:n1635. doi: 10.1136/bmj.n1635 pmid: 34167952

21 British Science Association. New survey results: almost 9 in 10 young people feel scientists and politicians are leaving them out of the covid-19 conversation. 2020. https://www.britishscienceassociation.org/news/new-survey-results-almost-9-in-10-young-people-feel-scientists-andpoliticians-are-leaving-them-out-of-the-covid-19-conversation.

22 Office for National Statistics. Coronavirus and vaccine hesitancy, Great Britain: 26 May to 20 June 2021. https://www.ons.gov.uk/peoplepopulationandcommunity/healthandsocialcare/healthandwellbeing/bulletins/coronavirusandvaccinehesitancygreatbritain/26mayto20june2021.

This article is made freely available for use in accordance with BMJ's website terms and conditions for the duration of the covid-19 pandemic or until otherwise determined by BMJ. You may use, download and print the article for any lawful, non-commercial purpose (including text and data mining) provided that all copyright notices and trade marks are retained. 